\title{
GENOTYPIC AND PHENOTYPIC DETECTION OF CAPSULAR POLYSACCHARIDES IN STAPHYLOCOCCUS AUREUS ISOLATED FROM BOVINE INTRAMAMMARY INFECTIONS IN ARGENTINA
}

\author{
C. Camussone ${ }^{1}$, P. Rejf ${ }^{3}$, N. Pujato ${ }^{2}$, A. Schwab ${ }^{2}$, I. Marcipar ${ }^{2}$, L.F. Calvinho ${ }^{1,3^{*}}$ \\ ${ }^{1}$ Estación Experimental Agropecuaria Rafaela, INTA. Ruta 34, Km 227, (2300) Rafaela, Santa Fe, Argentina; ${ }^{2}$ Facultad de \\ Bioquímica y Ciencias Biológicas, Universidad Nacional del Litoral, Paraje El Pozo, CC242, (3000) Santa Fe, Argentina; ${ }^{3}$ \\ Facultad de Ciencias Veterinarias, Universidad Nacional del Litoral, Rvdo. Padre Kreder 2805, (3080) Esperanza, Santa Fe,
} Argentina.

Submitted: February 28, 2011; Returned to authors for corrections: September 19, 2011; Approved: June 07, 2012.

\begin{abstract}
Staphylococcus aureus $(\mathrm{n}=157)$ isolated from intramammary infections in Argentine dairy areas were evaluated for presence of cap5 and cap 8 loci. Isolates carrying cap5 and cap 8 were serotyped using specific antisera. Sixty four percent of the isolates were genotyped as cap5 or cap 8 and 50\% of them expressed CP5 or 8 .
\end{abstract}

Key words: Staphylococcus aureus, capsular polysaccharides, bovine mastitis

Staphylococcus aureus capsular polysaccharides have been shown to confer resistance to phagocytosis by polymorphonuclear neutrophils (PMN), which are considered the main mammary gland line of defense against invading pathogens (5). Conversely, antibodies against CPs have a protective effect since they can opsonize encapsulated $S$. aureus from bovine origin for phagocytic killing by PMN (5).

The existence of $11 \mathrm{CP}$ serotypes has been proposed (13); however, only four types (CP1, CP2, CP5 and CP8) have been chemically characterized. Among them, CP5 and CP8 are the predominant serotypes in S. aureus isolated from human and bovine infections (13). Distribution of CP serotypes among $S$. aureus isolates from bovine milk from different countries shows variability $(6,15,23)$. A study carried out in Argentina found that only $14 \%$ from $195 \mathrm{~S}$. aureus isolates were typeable by serological methods (21). However, more than $70 \%$ of those isolates belonged to one province and only 9 isolates came from two provinces that concentrate about $60 \%$ of Argentina dairy production.

Capsular polysaccharides in vitro expression does not necessarily correlate with expression under in vivo conditions $(11,13)$. Therefore, surveys of CP prevalence taking into account only the in vitro phenotype, could underestimate the true distribution of virulent CP strains among a bacterial population. Up to now, the reports of CP prevalence have been mainly performed by in vitro phenotype analysis and only in few studies involving $S$. aureus from bovine origin, a subset of phenotyped isolates was typed by genetic methodology (21, 23).

Protection afforded by antibodies against CPs is related to their prevalence and type distribution in the population of isolates present in different regions (10). Therefore, the latter 
information is of paramount importance to estimate the usefulness of incorporating these components in a vaccine formulation. The aim of this study was to determine the prevalence and distribution of capsular genotype and phenotype of $S$. aureus isolated from bovine IMI in the four main dairy provinces of Argentina by genotypic and phenotypic methods.

One hundred and fifty seven $S$. aureus isolates were obtained between 2004 and 2007 from mammary secretion of cows with clinical or subclinical IMI, including a maximum number of 3 isolates from the same dairy herd. Isolates were confirmed to be $S$. aureus on the basis of conventional biochemical reactions. Isolates belonged to 83 dairy farms located in four Argentine provinces that concentrate more than 90\% dairy production of the country: Santa Fe ( $\mathrm{n}=91)$, Buenos Aires $(n=31)$, Córdoba $(n=22)$ and Entre Ríos $(n=13)$. From these isolates, 43 were from clinical and 91 from subclinical IMI; while for the remaining 23 isolates, the clinical origin was not determined. Clinical IMI was defined as presence of clinical signs in the mammary quarter (swelling, heat, pain) and/or changes in the appearance of milk; while subclinical IMI was defined as absence of clinical signs but somatic cell counts $>200,000$ cells $/ \mathrm{ml}$.

Genomic DNA was extracted from each isolate with a standard phenol-chloroform procedure (14). The presence of cap5k and cap8I loci was evaluated in all the isolates by Polymerase Chain Reaction (PCR). PCR was performed using genomic DNA as a template in a total volume of $25 \mu 1$ containing: 1x PCR buffer, $2 \mathrm{mM} \mathrm{MgCl} 2,0.25 \mathrm{mM}$ dNTPs

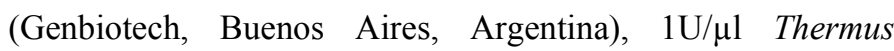
aquaticus DNA polymerase (PB-L, Argentina) and $0.2 \mu \mathrm{M}$ of the primers Cap5k1 (5'-GTCAAAGATTATGTGATGCTAC TGAG-3'), Cap5k2 (5'-ACTTCGAATATAAACTTGAATCA ATGTTATACAG-3'), Cap8k1 (5'-GCCTTATGTTAGGTGA TAAACC-3'), Cap8k2 (5'-GGAAAAACACTATCATAGCA GG-3') (Invitrogen Argentina, Buenos Aires) as described by Verdier et al. (24). Amplification was carried out on GeneAmp PCR System (Applied Biosystems, USA) using a program as follows: an initial 5-min denaturation step at $94^{\circ} \mathrm{C}$, followed by 30 cycles of $30 \mathrm{~s}$ of denaturation at $94^{\circ} \mathrm{C}, 30 \mathrm{~s}$ of annealing at $50^{\circ} \mathrm{C}$, and $1 \mathrm{~min}$ of extension at $72^{\circ} \mathrm{C}$; with a final extension step at $72^{\circ} \mathrm{C}$ for $5 \mathrm{~min}$. PCR products were analyzed by electrophoresis on ethidium bromide-stained 1.5\% agarose gels (Biodynamics, B.A. Argentina). The sizes of the amplicons were 361 bp for capsular type 5 and 173 bp for capsular type 8 .

Bacterial suspensions for preparation of typing sera were made from cultures of prototype $S$. aureus strains CP5 (Reynolds) and CP8 (Becker). These strains were isolated in 1979 from blood cultures at Kaiser permanent Hospital, North Hollywood, California (9) and were a kind gift from Dr. B. Poutrel (INRA, Nouzilly, France). Bacteria were grown on Columbia agar (Britania, Buenos Aires) supplemented with $2.5 \% \mathrm{NaCl}$, harvested and inactivated following previously described conditions (8). Two New Zealand white rabbits weighing $3 \mathrm{~kg}$ were immunized with each bacterial prototype according to the scheme described by Karakawa et al. $(8,12)$. Each rabbit serum was absorbed with $S$. aureus strain 57 , to remove antibodies to noncapsular antigens as previously described (8), aliquoted and stored at $-70^{\circ} \mathrm{C}$. CP from prototype strains 5 and 8 and all isolates typed by genetic method $(\mathrm{n}=101)$ were isolated as described by Fattom et al. (3). Polysaccharides concentration was determined by phenolsulphuric acid method (2), and presence of CP was visualized by SDS-Page and silver stain. Absence of proteins was verified by bicinchoninic acid assay (20) and SDS-Page followed by Coomassie Blue stain. ELISA assays were performed as follows: $5 \mu \mathrm{g}$ of purified CPs from isolates genotyped as carrying cap5 and cap 8 were used as antigens to sensitize 96well plates. Plates were blocked with PBS-powdered milk (5\%) and incubated with CP5 or CP8 antisera (1/200), respectively. Finally, a goat anti-rabbit $\operatorname{IgG}$ conjugated to alkaline peroxidase was used as secondary antibody, and the reaction was developed with TMB (Zimed). All incubations were carried out at $37^{\circ} \mathrm{C}$, for 60 minutes. Optical Densities (OD) were measured at $450 \mathrm{~nm}$ in an ELISA plate reader (Molecular Device). Chi square test was used to compare percent 
distribution of capsular types between provinces and to assess association between percent distributions of capsular types with regard to clinical origin of the isolates.

Sixty four percent of the isolates were typeable by PCR with specific primers for loci cap5 or cap8; being the rest of the isolates nontypeable (NT). Eighty three (52.87\%) isolates were genotyped as cap5 whereas eighteen (11.4\%) as cap8. None of the isolates positive for either cap5 or cap 8 genes was found to amplify both genes, confirming specificity of PCR used. Distribution of genotypes among isolates originated in different geographical areas is shown in Table 1. The prevalent capsular type among isolates from Córdoba, Santa Fe and Entre
Ríos was cap5. Conversely, the majority of isolates from Buenos Aires were NT, while type 5 was predominant among typeable isolates from this province. CP genotype distribution and percent of NT isolates varied between provinces; however, differences were not significant $(\mathrm{P}=0.227)$. More than $50 \%$ of the isolates from each province could be genotyped by the PCR methodology. Among isolates from clinical IMI, 31 (72.1\%) were genotyped either as cap5 or cap8, while only $12(27.9 \%)$ were NT. Among 91 isolates from subclinical IMI, 53 (58.2\%) were typed as cap5 or 8 and $38(41.8 \%)$ were NT (Table 2). Differences between percentages of typeable isolates according to the clinical origin were not significant $(\mathrm{P}=0.12)$.

Table 1. Distribution of capsular polysaccharide genotypes and phenotypes 5 and 8 among Staphylococcus aureus isolated from bovine intramammary infections in four Argentinean provinces.

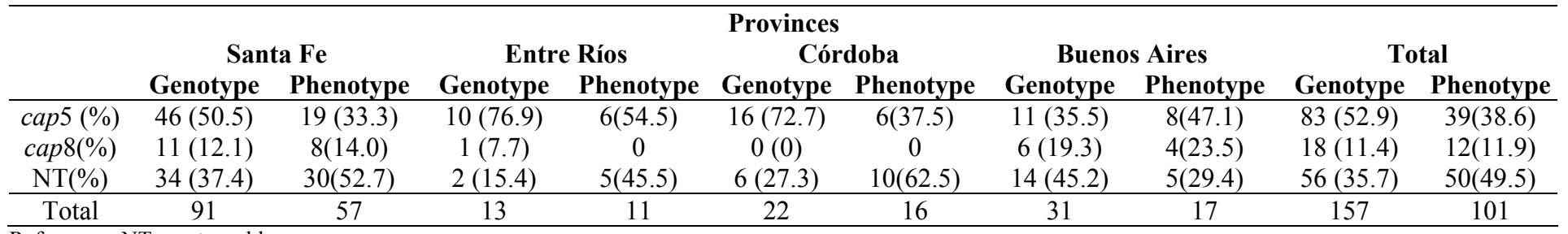

References: NT: nontypeable.

No differences in $\mathrm{CP}$ genotype $(\mathrm{P}=0.227)$ or phenotype $(\mathrm{P}=0.179)$ distribution were found between provinces.

Table 2. Distribution of $S$. aureus isolate types CP5 or CP8, according to mastitis clinical origin.

\begin{tabular}{ccccc}
\hline & \multicolumn{2}{c}{ Clinical } & \multicolumn{2}{c}{ Subclinical } \\
& Genotype & Phenotype & Genotype & Phenotype \\
\hline Typeable(\%) & $31(72.1)$ & $14(45.2)$ & $53(58.2)$ & $27(50.9)$ \\
NT(\%) & $12(27.9)$ & $17(54.2)$ & $38(41.8)$ & $26(49.1)$ \\
\hline Total & 43 & 31 & 91 & 53 \\
\hline
\end{tabular}

References: NT: nontypeable.

No statistical association between genotype $(\mathrm{P}=0.12)$ or phenotype $(\mathrm{P}=0.262)$ and clinical origin of the isolate was not found.

The isolates genotyped as cap5 and cap 8 were then tested with anti-CP5 and anti-CP8, respectively. The results of serotyping are shown in Table 1. Fifty percent of isolates genotyped as cap5 and cap8 were shown to produce CPs by ELISA for detecting either capsular type. Thirty nine isolates (38.6\%) reacted to anti-CP5 serum and 12 (11.9\%) to anti-CP8. From 83 isolates genotyped as cap5, 39 (46.9\%) were capable of expressing CP; while from 18 isolates genotyped as cap 8,12
(66.6\%) were capable of expressing CP.

A statistical association between the expression of CP5 or CP8 capsules and clinical origin of the isolate was not found (Table 2). From 84 isolates genotyped as cap5 and cap8 for which clinical status was known, 31 (37\%) where from clinical IMI, and among these isolates 14 (45.2\%) and 17 (54.8\%) were serotypeable and non serotypeable, respectively. Among isolates from subclinical origin, 53 from the 84 isolates were 
genotyped as cap5 and cap8 (63\%), and from these isolates 27 (50.9\%) and 26 (49.1) were serotypeable and non serotypeable, respectively.

Prevalence of isolates expressing CP5 and CP8 in this study $(32.2 \%)$ was lower than those observed in most previous reports of other countries $(6,15,23)$. A previous study carried out in Argentina, including 195 isolates, demonstrated that only $14 \%$ could be typed by specific antisera against CP5 or CP8 (21). In the present study, a higher prevalence of isolates expressing CP5 than previously reported (21) was observed; however, the percent of isolates expressing CP8 was similar in both studies. Differences in proportion of isolates expressing CP5 between studies can be explained mainly by the isolates geographical origin and the time frame of both studies. While most isolates from the previous study belonged to Buenos Aires province, $S$. aureus isolates included in the present investigation were obtained from the four main dairy provinces of Argentina. In addition, in the present study, to avoid bias produced by clonal dissemination, we included a maximum of 3 isolates per dairy farm to assure bacterial isolate diversity within each geographical area considered.

The low proportion of phenotype expression with respect to genotype presence was also reported in bovine mastitis isolates from Europe and USA (23). Genotype-phenotype disparity could indicate a restriction in phenotype expression due to differences between in vivo vs in vitro culture conditions $(16,17)$. This implies that conventional phenotypic evaluation can underestimate isolates ability to express $\mathrm{CP}$ in vivo. In addition, genotype-phenotype disparity could be due to the fact that some isolates carry cap genes but lack capsule expression due to mutations within capsule genes (1).

We found no association between genotype or phenotype and clinical origin of the isolate. In a previous study a significant association between CP8 expression and mastitis clinical manifestations was observed only for isolates from Ireland and Iceland (23). Recent studies have shown an association between $S$. aureus genotypes and IMI clinical and epidemiological features $(4,7)$; however associations in these latter cases were established with patterns including several rather than individual genes (4).

Presence of $\mathrm{CP}$ alone is considered to be insufficient to generate a protective immune response; however, their inclusion in a multicomponent vaccine would be useful to improve control of $S$. aureus IMI $(18,19,22)$. In addition, relevance of $\mathrm{CP}$ as candidates for generating protective responses is underscored by the fact that a commercial vaccine currently available for $S$. aureus mastitis control contains capsulated strains expressing 3 serotypes of CP present among the population of bovine isolates in USA (10). Sixty four percent of the isolates evaluated in this study carried cap5 and cap8 genes, which emphasizes the importance of including these components for rational design of mastitis vaccines.

\section{ACKNOWLEDGEMENTS}

We are grateful to Dr. Marcelo Signorini for technical assistance and to Dr. Liliana Tirante for providing S. aureus isolates from Buenos Aires province. This work was supported by grants from INTA (PNLEC1601) and ANPCyT (PICT 1175).

\section{REFERENCES}

1. Cocchiaro, J.L.; Gomez, M.I.; Risley, A.; Solinga, R.; Sordelli, D.O.; Lee, J.C. (2006). Molecular characterization of the capsule locus from non-typeable Staphylococcus aureus. Mol Microbiol. 59, 948-960.

2. Dubois, M.; Gilles, K.A.; Hamilton, J.K.; Rebers, P.A.; Smith, F. (1956). Colorimetric method for determination of sugars and related substances. Anal Chem. 28, 350-356.

3. Fattom, A.; Schneerson, R.; Szu, S.; Vann, W.; Shiloach, J.; Karakawa, W.; Robbins, J. (1990). Synthesis and immunologic properties in mice of vaccines composed of Staphylococcus aureus type 5 and type 8 capsular polysaccharides conjugated to Pseudomonas aeruginosa exotoxin A. Infect Immun. 58, 2367-2374.

4. Fournier, C.; Kuhnert, P.; Frey, J.; Miserez, R.; Kirchhofer, M.; Kaufmann, T.; Steiner, A.; Graber, H.U. (2008). Bovine Staphylococcus aureus: association of virulence genes, genotypes and clinical outcome. 
Res Vet Sci. 85, 439-448.

5. Guidry, A.J.; Oliver, S.P.; Squiggins, K.E.; Erbe, E.F.; Dowlen, H.H.; Hambleton, C.N.; Berning, L.M. (1991). Effect of anticapsular antibodies on neutrophil phagocytosis of Staphylococcus aureus. J Dairy Sci. 74, 3360-3369.

6. Guidry, A.; Fattom, A.; Patel, A.; O'Brien, C.; Shepherd, C.; Lohuis, J. (1998). Serotyping scheme for Staphylococcus aureus isolated from cows with mastitis. J Am Vet Med Assoc. 59, 1537-1539.

7. Hensen, S.M.; Pavicić, M.J.; Lohuis, J.A.; de Hoog, J.A.; Poutrel, B. (2000). Location of Staphylococcus aureus within the experimentally infected bovine udder and the expression of capsular polysaccharide type 5 in situ. J Dairy Sci. 83, 1966-1975.

8. Karakawa, W.W.; Fournier, J.M.; Vann, W.F.; Arbeit, R.; Schneerson, R.S.; Robbins, J.B. (1985). Method for the serological typing of the capsular polysaccharides of Staphylococcus aureus. J Clin Microbiol 22, 445-447.

9. Karakawa, W. W.; Vann, W. F. (1982). Capsular polysaccharides of Staphylococcus aureus. Semin. Infect. Dis. 4, 285-293.

10. Ma, J.; Cocchiaro, J.; Lee, J.C. (2004). Evaluation of serotypes of Staphylococcus aureus strains used in the production of a bovine mastitis bacterin. J Dairy Sci. 87, 178-182.

11. Nanra, J.S.; Timofeyeva, Y.; Buitrago, S.M.; Sellman, B.R.; Dilts, D.A.; Fink, P.; Nunez, L.; Hagen, M.; Matsuka, Y.V.; Mininni, T.; Zhu, D.; Pavliak, V.; Green, B.A.; Jansen, K.U.; Anderson, A.S. (2009). Heterogeneous in vivo expression of clumping factor A and capsular polysaccharide by Staphylococcus aureus: implications for vaccine design. Vaccine. 27, 3276-3280.

12. National Research Council (1996) Guide for the Care and Use of Laboratory Animals. Washington, DC: National Academy Press.

13. O'Riordan, K.; Lee, J.C. (2004). Staphylococcus aureus capsular polysaccharides. Clin Microbiol Rev. 17, 218-234.

14. Pospiech, A.; Neumann, B. (1995). A versatile quick-prep of genomic DNA from gram-positive bacteria. Trends Genet. 11, 217-218.

15. Poutrel, B. ; Boutonnier, A.; Sutra, L. ; Fournier, J.M. (1988). Prevalence of capsular polysaccharide types 5 and 8 among Staphylococcus aureus isolates from cow, goat, and ewe milk. J Clin Microbiol 26, 38-40.

16. Poutrel, B.; Gilbert, F.B.; Lebrun, M. (1995). Effects of culture conditions on production of type 5 capsular polysaccharide by human and bovine Staphylococcus aureus strains. Clin Diagn Lab Immunol. 2, 166-171.

17. Poutrel, B.; Rainard, P.; Sarradin, P. (1997). Heterogeneity of cellassociated CP5 expression on Staphylococcus aureus strains demonstrated by flow cytometry. Clin Diagn Lab Immunol. 4, 275-278.

18. Projan, S.J.; Nesin, M.; Dunman, P.M. (2006). Staphylococcal vaccines and immunotherapy: to dream the impossible dream? Curr Opin Pharmacol. 5, 473-479.

19. Shaffer, A.C.; Lee, J.C. (2008). Vaccination and passive immunization against Staphylococcus aureus. Int J Antimicro Ag. 325, 571-578.

20. Smith, P.K.; Krohn, R.I.; Hermanson, G.T.; Mallia, A.K.; Gartner, F.H. ; Provenzano, M.D.; Fujimoto, E.K. ; Goeke, N.M.; Olson, B.J.; Klenk, D.C. (1985). Measurement of protein using bicinchoninic acid. Anal Biochem. 150, 76-85.

21. Sordelli, D.O.; Buzzola, F.R.; Gomez, M.I.; Steele-Moore, L.; Berg, D.; Gentilini, E.; Catalano, M.; Reitz, A.J.; Tollersrud, T.; Denamiel, G.; Jeric, P.; Lee, J.C. (2000). Capsule expression by bovine isolates of Staphylococcus aureus from Argentina: genetic and epidemiologic analyses. J Clin Microbiol 38, 846-850.

22. Stranger-Jones, Y.K.; Bae, T.; Schneewind, O. (2006). Vaccine assembly from surface proteins of Staphylococcus aureus. Proc Natl Acad Sci USA. 103, 16942-16947.

23. Tollersrud, T.; Kenny, K.; Reitz, A.J.; Lee, J.C. (2000). Genetic and serologic evaluation of capsule production by bovine mammary isolates of Staphylococcus aureus and other Staphylococcus spp. From Europe and the United States. J Clin Microbiol. 38, 2998-3003.

24. Verdier, I.; Durand, G.; Bes, M.; Taylor, K.; Lina, G.; Vandenesch, F.; Fattom, A.; Etienne, J. (2007). Identification of the capsular polysaccharides in Staphylococcus aureus clinical isolates by PCR and agglutination tests. J Clin Microbiol. 45, 725-729. 